\title{
Editorial
}

\section{Chile: nuevos desafíos en políticas públicas materno-infantiles}

En la Cumbre del Milenio de Naciones Unidas, realizada el año 2000 , la comunidad internacional definió 8 grandes Objetivos de Desarrollo del Milenio (ODM), cuyas metas debieran lograrse el año 2015. Entre estos Objetivos se encuentra la reducción de la mortalidad infantil (ODM 4) y la mejoría de la salud materna (ODM 5). El logro de estos objetivos, directamente relacionados con la condición de la mujer, en particular, con su capacidad para utilizar y valorar los servicios de atención en salud, involucra avanzar también en el ODM 3 , de promover el empoderamiento de la mujer (1-3).

Para los Objetivos 4 y 5 se definen metas específicas a alcanzar en el año 2015: disminuir la mortalidad infantil en menores de 5 años de edad en dos tercios $(66 \%)$, y la mortalidad materna en tres cuartos $(75 \%)$, comparadas con las tasas del año 1990. Los indicadores propuestos son: tasa mortalidad infantil (TMI) en menores de 5 años, razón de mortalidad materna (RMM), cobertura de atención profesional del parto y acceso universal a la salud reproductiva (4-5).

A nivel global se han logrado progresos importantes, reduciendo desde aproximadamente 500 mil muertes anuales en el año 1990 (RMM de 400/100.000 nv), a aproximadamente $287 \mathrm{mil}$ muertes en el año 2010 (210/100.000 nv) (rango: 170 a 300/100.000 nv), es decir una disminución de más de un $40 \%$. Este período histórico de observación tan estricta ha permitido demostrar la enorme inequidad en la situación materna a nivel global y regional. Así la meta propuesta ha sido alcanzada solo por una minoría de países, fundamentalmente del Este de Europa. En su gran mayoría (99\%), los países con peores indicadores han logrado a su vez progresos menores (1-5).

En la región, se observa una tendencia sostenida a la mejoría de estos indicadores maternoinfantiles, pero aún insuficiente para alcanzar las Metas del Milenio el 2015, particularmente cuando se analiza la tendencia desagregada a nivel de paí- ses (6-8). Nuestra región presenta una situación de inequidad inaceptablemente alta, la que se expresa por la persistencia de indicadores significativamente mayores en poblaciones con menores niveles de ingreso y educación, en poblaciones rurales, y en pueblos indígenas.

Chile ha presentado al igual que Uruguay, Cuba, Costa Rica y Méjico progresos significativos en el indicador de mortalidad materna, alcanzando porcentajes significativos de reducción en aproximadamente $50 \%$ en los últimos veinte años. A nivel nacional al alcanzar indicadores de menos de veinte muertes maternas por cien mil nacidos, el perfil etiológico ha cambiado de ser predominantemente de causas directas $u$ obstétricas a principalmente causas indirectas o patologías médico-quirúrgicas asociadas al embarazo (6-8).

En la evaluación de un indicador tan sensible como el de mortalidad materna, se debe analizar además el grado de equidad en su distribución, así como también la tendencia observada. Estos dos últimos aspectos son dentro de una realidad materno-infantil aceptable, signos de alarma importantes para nuestro país: una inequidad persistente y un estancamiento de la situación materna en el último decenio.

Chile, fiel a la gran valoración social otorgada por su pueblo a la maternidad y a la niñez, concordante con su historia de priorizar políticamente los aspectos materno-infantiles, debe promover la discusión de nuevas estrategias para mejorar esta situación. Las instituciones encargadas de ello deben promover la discusión al más alto nivel que genere nuevas políticas públicas orientadas a innovar y mejorar la situación en esta área. Parafraseando un editorial de la revista Lancet "todos sabemos lo que se debe hacer", debemos reinstalar el tema y quebrar esta ausencia de progreso en la salud de nuestras madres.

La Sociedad Chilena de Obstetricia y Ginecología, el Ministerio de Salud y la Pontificia Univer- 
sidad Católica de Chile, junto a la valiosa colaboración de expertos internacionales provenientes de Canadá y del Centro OMS-Rosarino de Estudios Perinatales, han organizado una reunión de trabajo sobre mortalidad materna en nuestra región, ha realizarse en Concepción, Chile, el próximo 12 y 13 de Noviembre de 2012. Es esperable que en este Workshop se genere un documento de consenso propositivo, que esperamos impacte positivamente en la mejoría de la salud materna y de las niñas y niños de nuestro país.

Dr. Rogelio González P. Coordinador Workshop Mortalidad Materna.

\section{REFERENCIAS}

1. Hogan MC, Foreman KJ, Naghavi M, Ahn SY, Wang M, Makela SM, et al. Maternal mortality for 181 countries, 1980-2008: a systematic analysis of progress towards Millennium Development Goal 5. Lancet 2010;375(9726):1609-23.

2. Waage J, Banerji R, Campbell O, Chirwa E, Collender G, Dieltiens V, et al. The Millennium Develop- ment Goals: a cross-sectoral analysis and principles for goal setting after 2015 Lancet and London International Development Centre Commission. Lancet 2010;376(9745):991-1023.

3. Campbell OM, Graham WJ; Lancet Maternal Survival Series steering group. Strategies for reducing maternal mortality: getting on with what Works. Lancet 2006;368(9543):1284-99.

4. WHO, UNICEF, UNFPA and The World Bank. Trends in Maternal Mortality: 1990 to 2008. Estimates developed by WHO, UNICEF, UNFPA and The World Bank. World Health Organization 2010.

5. United Nations. The Millennium Development Goals Report 2011. Disponible en: http://www.un.org/millenniumgoals/11_MDG\%20Report_EN.pdf.

6. Donoso E. Mortalidad Materna en Chile, 2000-2004. Rev Chil Obstet Ginecol 2006;71(4):246-51.

7. Koch E, Thorp J, Bravo M, Gatica S, Romero CX, Aguilera $\mathrm{H}$, Ahlers I. Women's education level, maternal health facilities, abortion legislation and maternal deaths: a natural experiment in Chile from 1957 to 2007. PLoS One 2012;7(5):e36613.

8. González R. Salud Materno-Infantil en las Américas. Rev Chil Obstet Ginecol 2010;75(6):411-21. 